\title{
The Business Case for Effective Mine Closure
}

\author{
P. Dowd Newmont Australia Ltd, Australia \\ M. Slight Newmont Australia Ltd, Australia
}

\section{INTRODUCTION}

The subject of this keynote address is to demonstrate the business case for effective mine closure.

To demonstrate the points that will be raised in this address, I will be referring to the approach that the Newmont Mining Corporation (herein referred to as "Newmont") and its subsidiary, Newmont Australia Limited (herein referred to as "Newmont Australia"), takes with regard to what it considers "effective mine closure".

In simplest terms, effective mine closure is about creating sustainable outcomes where possible, minimising the negative environmental, social and economic impacts for the communities the mine operates in and minimising closure liabilities by conducting rehabilitation activities progressively with operations. The key value add and hence business case comes from incorporating closure planning, and water and waste management decisions in the mine planning process to maximise efficiencies in material handling, minimise disturbance footprints and use valuable surface and groundwater resources in an eco-efficient manner. There is also the possibility of building economic opportunities throughout the life of the mine which may provide a platform for future sustainable activities.

There are 3 key messages I wish to deliver:

- Closure must be integrated within the mine planning process.

- Planning and decision making processes should recognise closure issues such as progressive rehabilitation and long term ARD.

- Delivering on our social responsibility through the Newmont systems and standards.

Planning for Closure is fundamental to the responsible operation of any mining company with closure integrating across a number of aspects including health and safety, environment, local economic impacts and external/community relations and financial.

A key element of this process is to engage early with the community and relevant stakeholders in the planning of the project including closure. For Newmont to contribute positively to a mining project development and build the wealth of its shareholders and reputation within the communities in which it operates, closure objectives and impacts are ideally considered from the very inception of a project right through to the relinquishment of the mineral tenement.

Projects in the planning phase have a strong opportunity for reducing potential liabilities and maximizing sustainable closure options. Projects in the middle of their operating life have slightly less opportunities, and projects close to the end of the life cycle life have more limited options for addressing closure issues and impacts with sustainable solutions.

Planning is required to enable a company to be adequately prepared and resourced for mine closure at any time. There are usually two broad closure scenarios:

- Planned - operations run to target completion dates for resource extraction.

- Unplanned/Sudden - operations close due to economic market changes, company finances, technical or structural failures or temporary closure.

Projects have to be prepared for both of these scenarios. 
Closure policies and plans should define the vision of the end result of a mining project and contain concrete objectives for implementing that vision. The primary objectives of closure can be broadly defined as follows:

- Reduce or eliminate adverse environmental, economic and social impacts and liabilities of mine closure.

- Establish conditions which meet stakeholder expectations, including regulators and the community for a sustainable benefit beyond the life of the mine.

This just makes good business sense and is what Newmont terms their Social License to operate.

\section{BACKGROUND}

Newmont is one of the world's largest gold producers. It's a US based mining company, with annual production of approximately 7 million ounces, a market capitalisation of US\$16 B, with mining operations on 5 continents. As part of its financial reporting protocols, Newmont estimates the cost of mine closure and rehabilitation of its operations to satisfy regulatory and accounting obligations.

Newmont's current estimated closure liability is in the order of several hundred million dollars globally. Of this, the cost associated with waste management (tailings, process water and waste rock) accounts for approximately $2 / 3$ rds of Newmont's closure and rehabilitation liability. It is immediately apparent that a well organised, planned and implemented waste management program can have a significant economic impact on the financial performance of a company such as Newmont - just a $10 \%$ reduction in liability is worth tens of millions of dollars in direct benefit to Newmont's global Net Asset Value (NAV).

Closer to home, Newmont Australia has 5 active mining operations, 1 site in development, 1 site in closure, 2 sites in care and maintenance, 3 sites in post closure monitoring and several exploration regions located across Australia and in New Zealand. Newmont Australia's estimated closure costs for sites in which it maintains a financial interest is in the order of USD $\$ 150 \mathrm{M}$ of which greater than $65 \%$ is for "waste management". There is a mixture of underground and open pit operations, of which some are located very close to population centers, and others located incredibly remotely. One such mine is the Tanami mining operations, located $500 \mathrm{~km}$ north of Alice Springs - this operation is the most remote in Australia and situated on Aboriginal freehold land. The point here is that wherever Newmont has mining operations there are external stakeholders who can determine the future success of the company as much as its employees.

The importance of effective mine closure planning to Newmont is driven from two standpoints:

- Short term economic benefit, through efficiencies and productivity gained through strategically integrated mine operations and closure plans.

- Long term economic benefit, through the establishment of excellent relationships with key stakeholders that leads to longevity of operations and the establishment of new projects.

\section{CLOSURE PLANNING PROCESS}

Newmont has established a comprehensive project life cycle planning process that applies to all its projects. The process is tailored to meet the various socio-economic and environmental closure requirements at each phase of the project life cycle.

Closure plans are most effective when integrated into the day-to-day operations and implemented throughout the life cycle of a project. They cover financial and operational aspects, as well as environmental social, community and employee issues. While Closure Plans will vary from project to project, the processes for closure planning are the same the world over.

The closure criteria are an important part of any closure plan, as no mine can be considered closed or have completed closure until stakeholders have agreed that the required outcomes have been attained. Closure criteria are best defined early in the project life cycle when Environmental and Social Impact Assessments are undertaken. 


\subsection{The Project Feasibility, Design and Construction Stage}

Newmont facilities consider and incorporate socio-economic and environmental closure issues and impacts into the design and construction of all their new development projects such that the opportunity for meeting post-closure land use objectives at the time of closure is maximized. A "stage gate" capital development process has been implemented globally which requires incorporation of environmental and social aspects including detailed closure plans for the project in the decision making process. The project cannot proceed unless the plans are reviewed, modified if required and approved by senior management.

The design and construction phase of any new project should include as a minimum the following:

- Environmental and social impact assessment processes that includes both operational and postclosure, decommissioning risks and opportunities. This will include but not be limited to waste characterisation, tailings and water management, and land form stability.

- Identification of key stakeholders related to closure and post-closure.

- Stakeholder analysis that includes the capacity of stakeholder groups to understand and address the impacts of closure.

- Design and construction of infrastructure that takes into account post closure community use and cultural value, long term environmental impacts and required mitigation plans and is based on engagement with key stakeholders.

- Design/construction plans must be linked to longer term community development activities and capacity-building activities.

- The facility closure and reclamation plan should incorporate socio-economic factors and associated in the technical and financial evaluation of any new, or modification to, project, site or facility.

\subsection{The Operations Stage}

The environment and socio-economic aspects of the feasibility, design and construction based closure and reclamation plan is reviewed at completion of the construction phase of a project. A review of this phase of a project will reveal any deficiencies in the planning process that would be included in the operations phase and for future project development. This will also apply where the project undergoes an expansion to its operations.

The environment and socio-economic aspects of the closure and reclamation plan during the operations phase is required to be:

- Informed by environment and social impact assessments and assessments of post-closure impacts.

- Linked to the project's operational environment and external relations strategic management plans.

- Used to inform and support the operations objectives and targets.

- Have an appropriate budget, timeline and resources to pre-plan and carry out activities including progressive reclamation and rehabilitation and water management.

- Regularly updated and reviewed by senior management.

- Based on engagement with a range of external stakeholders.

- Supportive of wider community, regional and national development plans beyond the life of the mine, particularly economic diversification.

- Developed with a cross-functional team from the environment and social responsibility department, human resources, and the project operations' departments including mine planning and production.

- Compliant with all relevant legal obligations.

- Approved by and signed off by corporate senior management. 
During the operations phase the closure plan should consider:

- A transition plan as the operation moves closer to closure (generally 3 years from closure) for local employees including up-skilling, retraining and relocation options. This would include external resources to provide the support services needed for successful implementation.

- A transition plan for local business including exploring additional longer term sustainable business enterprises that could support the project as it moves into the post closure monitoring phase.

- Consideration of the development of "safety net" schemes for the most vulnerable groups in the communities surrounding the project.

- Support for training and use of local suppliers for post-closure activities including environmental monitoring and care and maintenance activities such as weed, feral animal and fire management.

- A transition plan for the disposition of all physical assets belonging to the project including any opportunities for community support.

- A transition plan for the sustainability of all external relations and community investment activities and programs.

- Consideration of a strategy for capacity building for organisations and groups with responsibilities and interests in closure and post-closure issues associated with the project.

- A transition plan for the continued protection of all sites with cultural, historical or religious significance and all documents relating to these sites during closure and the post closure phases.

- The development of an external and internal communication plan of all closure plans including the transition plans.

- The establishment of a monitoring plan for the closure and post-closure period addressing all environmental and socio-economic initiatives.

- The development of contingency plans for other exit strategies alternatives such as sale of the project.

- The establishment of appropriate financial mechanisms to ensure the ability to fund capacity building, closure and post-closure activities including land care aspect, designed to address all environmental and social closure risks and opportunities including taking into account potential significant post closure risk environmental event mitigation plans.

- The plans should clearly define roles and responsibilities for all personnel involved in the closure and post-closure activities.

Once the project closure is triggered at the end of operations the planning process developed during the operations phase must be implemented and will provide the most benefit to the project. Communication and implementation of the closure plan should include:

- Continued communication of closure activities to interested and affected stakeholders. This will be required during the post closure phase as well.

- Implementation of all aspects of the plans, including the handover of the management of any ongoing community programs.

- Processes to evaluate the effectiveness of all the environmental and social monitoring programs including audits, assessments, peer reviews and social impact assessments.

Newmont has developed a step by step check list approach to closure planning in all phases of the project life cycle. The closure process adopted by Newmont globally is not meant to be a linear process, as some projects will need to repeat certain steps, as necessary during its life cycle. The following summarises the planning approach and is applied through Newmont's 5 Star management standards and guidelines for both environment and social responsibility disciplines: 
- Each project should define staff roles, responsibilities and resources for closure planning early and this step will require the project management team to be assigned the responsibility and accountability to take the lead in the closure planning and implementation at each phase of the project life cycle.

- The project team should establish and/or consult with stakeholder representative group/s either through a consultative or liaison committee approach on all aspects of the project including the closure planning process.

- The team must identify closure issues and opportunities (jointly with stakeholders) including environmental, operational and socio-economic issues. This means that relevant data and studies may be required during each phase of the project to develop models to measure the performance during the phase.

- The project team must undertake social impact assessment studies and/or other studies to better understand social/community/employee issues and develop possible solutions.

- The project team should communicate the findings of studies and research and discuss interpretation with stakeholders.

- A risk assessment of potential issues and opportunities must be undertaken during the planning process. This risk assessment should be done as a team based assessment utilizing the skills and knowledge of the project closure team and any additional external expertise that may be required.

- The project team will refine closure strategies including closure criteria and post closure monitoring and management requirements at the start of each stage in the project cycle and should be reviewed annually.

- The closure criteria should be agreed by all stakeholders prior to closure wherever possible.

- The project team should seek necessary regulatory approvals of the closure plan during the various phases of the project and prior to closure. The closure plan will require updating as required and a post closure plan will be required following closure leading up to lease relinquishment.

- The planning process must include a communication plan to enable presentation and discussion of closure monitoring results and outcomes with all stakeholders.

Processes used for closure planning and implementation are extensive, comprising many sub-processes. Newmont utilises its Integrated Management System and associated internal Five Star Guidelines to assist. Key social management system standards include the following:

- Stakeholder engagement.

- Ideally the closure plan and in particular the closure criteria would be discussed and jointly agreed with stakeholders, including communities who might be affected, as well as employees, local businesses and relevant regulatory authorities. A strategy for monitoring and review should also be agreed.

- Projects can also consider establishing a Closure Committee in multi-stakeholder forum. There should be some common membership with other stakeholder committees involved in the resolution of other issues throughout the life of mine.

- Social Impact Assessment (SIA).

- SIA's should ideally be conducted during pre-feasibility studies, during operations on a regular basis and at least 1-2 years prior to closure. SIA consultations should be broad and inclusive, and for operating projects, include current/past site personnel. The project should ensure the inter-generational issues and impacts are also considered.

- Risk assessments.

- Once issues around mine closure have been identified, a risk assessment should be undertaken to rank issues associated with closure, based on actual or perceived impact. This 
should include managing potential liabilities after closure and identifying opportunities created by the closure of the mine (e.g. innovative land use, establishing new local industries etc.).

- Local community investments.

- In making local community investments with a view towards closure, projects should consider equitable distribution of benefits so that future generations, who may continue to live with the impacts of mining, also benefit. Investments should also consider community capacity beyond the life of mine to deal with impacts and issues.

- It may be necessary to establish a trust fund or foundation that would operate beyond the life of the mine to support local community development and provide for the land care aspects and risks associated with the project post closure. Governance of these bodies should be carefully considered to ensure transparent, accountable and effective management and disbursement of these funds based on the agreed outcomes.

- Local employment and business support.

- Local staff, contractors and other businesses reliant on mine operations will need to adapt to the closure of the mine. Training and support to staff and businesses should consider from the outset the transferability of skills and the ability to reduce reliance solely on the mine. This might require working in partnership with other local industries to ensure local development opportunities beyond the life of the mine.

\subsubsection{Example 1 - The business case for planning for progressive rehabilitation}

Progressive rehabilitation requires a comprehensive mine plan to be in place, to ensure that reserves are well understood, that waste volumes are properly calculated and that final contours and waste dump characteristics are optimised, given this information. In turn, better mine planning provides more certainty of operational result, allows for pro-active management, which in turn allows for strategic thinking for the future to take place. All of these add value to any mining operation.

Progressive rehabilitation minimises the obvious effects of mining, provides objective evidence of the company's intentions and minimises the potential for a reputation breaking event to occur.

Stakeholders should be involved very early on, allowing them a say in what final landforms may look like, or whether open pits should be filled or not. In addition stakeholders can be made aware of the strict environmental standards required by regulatory bodies and how companies meet and frequently improve on the requirements set. Indeed stakeholders can become a company's biggest ally, supporting it when regulatory requirements are being established by the relevant authorities.

In Newmont's case we have seen the recent permitting of the Favona underground mine in New Zealand completed without public hearing, and saving potentially half a million dollars that would otherwise be spent on appeal hearings etc. This is real value add.

In the Tanami, the local indigenous representatives endorsed a plan to back fill open pits with tailings, in fact insisted on it, eliminating the need to build new storage facilities, and minimising the "footprint" that the mine will eventually have - again an example of real value add.

Stakeholders can affect the short term outcomes at a mining operation to add value - but the real value is in future operations. With effective stakeholder engagement during all stages of a project, mining companies can actually become the miner of choice, due to a credible track record and the promise of the same in the future, such that their land applications are treated as a priority, or permitting is expedited to ensure that delays are minimised, or objections to proposed developments are minimal. It is suggested that a company with a poor track record in closure at its operations will struggle to convince anyone that it is a good option for a new development going forward.

The additional resources required to complete progressive rehabilitation are small, and are likely to be cheaper than those required for a post closure rehabilitation exercise. The synergies available, while a mine is still operating, will more than offset additional resources required for a stand alone closure operation. 
These synergies include the ability to use equipment, messing facilities, aircraft at Fly in Fly out (FIFO) operations, power, water, communications, computer networks etc. In addition personnel are frequently available to manage and do the work, alleviating the need to try and find experts once operations have been completed. With appropriate planning during the mining operation, different types of waste rock (potentially acid forming [PAF], non acid forming [NAF]) can be strategically mined and placed to minimise future environmental impacts and the necessity to double handle material in the future - a very expensive exercise.

Finally, progressive rehabilitation provides an opportunity to recognise potential problems early and to take steps to mitigate them, rather than have them appear when all the equipment and people have left - in turn requiring a greater expenditure to re-mobilise.

Progressive rehabilitation, and completing reclamation as soon as possible once the mine has closed, also reduces the financial burden of bonds going forward. Bonds cost cash to hold and also reduce the amount of borrowing a company can access going forward - so their early elimination is a benefit to the company, and one less liability.

The ability to sell projects improves if rehabilitation is well underway - the purchaser seeing the opportunities in front of it with new ore bodies or greater efficiencies and productivity, rather than seeing a liability in the form of open holes, messy waste dumps with dirty run off, uncapped drill holes and large uncapped tails dams. In selling a project though, it is recommended that the purchaser be required to follow established closure plans so that the good work done by the company is not undone by an incumbent that may have lower quality criteria for the closure of its operations - again this is a reputation issue.

\subsubsection{Mt McClure Gold Mine, Western Australia case study}

The Mt McClure gold mine operated a number of open pits in the 1990s. Whilst progressive rehabilitation was not undertaken during the life of the mining operations, the leases became part of the Newmont Bronzewing operations, allowing planning and implementation of rehabilitation to take place while infrastructure and people were still available at Bronzewing. Key points to note are:

- Closure of Mt McClure was completed within 60 days of Bronzewing concluding its operations.

- The closure utilised resources (equipment, management etc) that already existed at Bronzewing.

- The company held a stakeholder workshop which included government, graziers and Traditional Owners to ensure that their concerns and ideas were incorporated into the plan.

- An unsafe plant was dismantled and removed at no cost.

- Over $10000 \mathrm{oz}$ of gold, worth over AUD\$5 M was recovered from the site whilst facilities remained in place at Bronzewing to process it.

- Two tailings dams and five waste dumps were rehabilitated.

- On conclusion of the project the site won one of two Golden Gecko Awards, awarded by the Western Australia Government in recognition of excellence (2004). This provided external recognition of Newmont's capability and commitment, in turn enhancing Newmont's "Social Licence to Operate".

- Newmont sold Bronzewing to View Resources without fear of reputation damage to Newmont.

\subsubsection{Example 2 - The business case for planning for the prevention of acid mine drainage}

It is Newmont's belief that acid drainage can be prevented if some key principles are followed throughout the life of a mine, from exploration through to closure. The most important principles are:

- The focus must be on the prevention rather then treatment.

- The project must ensure there is an understanding of the physical and chemical characteristics of all ore, waste rock types and tailings. 
- Getting the planning and design wrong can cause enormous cost blow-out at closure and create a significant liability well into the future.

- The cost of rehabilitation and closure must be rigorously estimated and accounted for during all phases of the project life cycle starting at the feasibility stage and during operations.

- The Integration of mine rehabilitation works into the day to day mine operations will minimise final reclamation costs.

- Accurate delineation of PAF and NAF during construction and operations is essential.

- Quality control of engineering works is essential.

Newmont has developed a simple model that can be used to present the business case for preventing acid drainage. This model outlines the opportunities for Newmont if we get it right and the risks if we get it wrong. The model also highlights the fact that we have a diminishing opportunity to get it right as we move through the life cycle of a mine from discovery to final closure.

\subsubsection{Waihi Gold Mine in New Zealand case study}

The Waihi Operation in New Zealand is one of the best examples of effective planning and design to prevent acid drainage within Newmont. During the permitting process for the Open Pit Extension Project in 1998/1999, which included a new tailings storage facility, acid drainage was a contentious issue, and measures proposed to control acid rock drainage were subject to very thorough investigations.

This was a result of a potentially crippling ARD problem in the existing tailings storage facility in 1993 and 1994 which resulted in significant effects on both surface and groundwater quality. Although there was no direct regulatory action at this time, the regulators and community were acutely aware of the potential risks associated with acid drainage. This issue manifested itself during the permitting of the Extension Project, and severely tested the viability of the project. Extra permitting relating to water quality added several million dollars to permitting costs and delayed the project by many months.

The key design features that were presented to the Regulator and the community as evidence that this project could be engineered, operated and closed to high environmental standards were:

- The addition of limestone to potentially acid forming (PAF) waste rock to suppress acid generation in the waste rock.

- Complete integration of waste rock and tailings placement to form a single stable landform.

- Embankment and underdrainage design features that encapsulate PAF material and control seepage.

Construction of the embankments required the selective use and zoning of waste rock materials and the controlled placement of waste rock fill.

Embankment zoning provided for:

- Restriction of tailings seepage.

- Safe long-term stability under both static and seismic loads.

- Control of generation of acid drainage in the short and long term.

- Collection of tailings seepage and waste rock leachate for treatment.

- Rehabilitation of the downstream shoulder to pasture and native plantings.

PAF material is placed upon a low permeability under-blanket and drains collect any leachate that is generated. Oxygen and water ingress is limited by rolling and compaction of the waste rock, and the construction of intermediate sealing layers at regular intervals. During construction, crushed limestone is applied to exposed PAF rock to control acid generation.

In the long term, generation of acid leachate is prevented by isolating PAF rock from atmospheric oxygen by the construction of a special layer on the outside of the embankment. This acts both as an oxygen diffusion barrier and controls infiltration of water into the embankments. 
Materials are selected so that when compacted they provide a lower permeability fill with a higher level of saturation. This layer only allows a small amount of water to move through it slowly. The slow movement of water through this layer ensures that this layer is near saturated, all of the time and there is no easy path for air containing oxygen to enter the waste rock.

\section{CONCLUSION}

There are many challenges facing the mining industry not the least of which are the technical challenges. However one of the most important challenges facing us is the importance of developing people to sustain our industry in the future.

Newmont's "people issue" challenges are recognised through the high turnover is currently being experienced in the industry and the resultant, corporate memory loss. The challenges are:

- How do we make sure that decisions that have long term implications are made by people who have the vision and foresight to understand the social and environmental implications of their decisions?

- How can we maintain the continuity of corporate memory and more particularly the level of knowledge required at our operations to ensure that the original planning and design principles are met during the operating life through to closure? How many times do we see this requisite knowledge wax and wane as people turnover at our sites?

Some approaches that Newmont have taken:

- Systematise work through the planning processes at all stages of the project life cycle.

- Integrate systems into the business, so that important decisions become institutionalised.

- Ensure change management processes are planned for and followed, so that broader implications of operational changes are understood and acted on.

- Build competencies throughout our business so that we all understand the importance of our roles in the context of the broader business. For example:

- A mine planner must understand the environmental implications of mine design.

- A process plant superintendent must understand the risks and longer term liability issues associated with operating a tailings facility and ensure that adequate controls are in place.

- Build capacity by working with education institutions as an industry and by creating links from within our companies (Importance of: INAP, ACMER, MCA, SMI, CSRP and our Universities).

- Encourage a continuous improvement culture and give people the freedom to contribute beyond their core roles. Encourage innovation. 